\title{
ОСОБЕННОСТИ ОРГАНИЗАЦИИ АКТИВНОСТИ МОЗГА В СОСТОЯНИИ ВЛЮБЛЕННОСТИ
}

\author{
Исслед.выполнено в рамках НИР 0138-2021-0002 и при финансовой \\ поддержке ФГБОУ ВО МГППУ \\ Сомик Л.Е. (Институт психологии РАН, Москва, Россия) \\ frankie7floyd@gmail.com
}

Гаврилов В.В. (Институт психологии РАН, Московский государственный психолого-педагогический университет, Москва, Россия), nvvgav@mail.ru

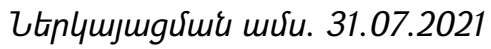

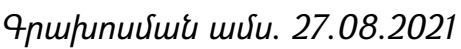

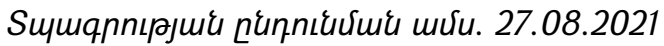

Влюбленность рассматривается как нехимическая зависимость. Одной из важнейших особенностей аддиктивного поведения является непрерывный фокус внимания на определенных объектах и развитие интенсивных эмоций. Целью исследования было выявление особенностей организации активности мозга в состоянии влюбленности. Основным методом выявления влюбленности был выбран автобиографический метод каузометрии LifeLine [1]. Испытуемых просили назвать 15 самых важных событий в их жизни, а затем провести анализ связей этих событий между собой. Кроме того, испытуемые отвечали на вопросы из опросника «Шкала страстной любви» [6]. Была выявлена значимая корреляция между данными опросника и данными полученными в LifeLine. B каузограмме у влюбленных испытуемых одним из доминирующих является событие, связанное с возлюбленным. Выявлены различия между потенциалами субъектов, находящихся в состоянии влюблённости, и не находящимися в данном состоянии, а так же при актуализации событий, связанных с влюбленностью, и актуализации других важных событий из других доменов.

Ключевые слова: влюбленность, нехимическая аддикция, электроэнцефаллограмма, LifeLine.

DOI: https://doi.org/10.46991/SBMP/2021.4.2.313

Решение проблемы аддикций, как химических, так и нехимических, чрезвычайно важно и является актуальным до сих пор. По мнению многих исследователей, влюбленность является нехимической зависимостью $[2,3$, и 
др.]. По мнению Э. Хэторилд и С. Шпрехер [6] такое состояние отличается изменениями в эмоциональной, поведенческой и когнитивной сфере (навязчивые мысли о партнере, идеализация партнера). Среди сравнительно немногочисленных психофизиологических исследований этой проблемы следует отметить сравнение активности мозга влюбленных людей и наркоманов с помощью фМРТ [5, 7], на основании которого был сделан вывод о сходстве активности мозга при химической зависимости и влюбленности. Несмотря на интерес к этой проблеме, в настоящий момент не существует общепринятой методики определения состояния влюбленности. Часто критерием отнесения человека в контрольную или экспериментальную группу являлся лишь ответ на вопрос: «Вы влюблены?» В других исследованиях используется метод опросника, который тоже часто подвергается критике, на наш взгляд, справедливой. Именно по этим причинам, одной из целей данной работы, была проверка гипотезы о том, что можно использовать метод каузометрии (LifeLine) для более объективного выявления состояния влюбленности. Методологической основой данного исследования яляются представления системно-эволюционного подхода (СЭП) [4]. В СЭП любое субъективно важное событие является элементом опыта и «фиксируется» в виде активности специализированных относительно этого события нейронов, представляющих систему события. Эта система имеет определенные отношения с другими системами, которые актуализируются в разной степени при актуализации данной системы. Поскольку разные субъекты имеют разную историю жизни (отношений с фризической и социальной средой), то и структура их индивидуального опыта разнообразна. Мы исходили из того, что в состоянии влюбленности субъекты при просьбе назвать самые важные события их жизни будут называть среди наиболее важных событий, события, связанные с объектом их любви. Актуализация этих элементов опыта возможно будет по иному отражаться в потенциалах ЭЭГ, чем актуализация других, не связанных с влюбленностью элементов опыта. Таким образом, при регистрации суммарной электрической активности мозга электродами, расположенными над разными областями мозга, будут установлены особенности межсистемных отношений (отношений между элементами опыта) при влюбленности. Кроме того, можно предположить, что элементы опыта в домене «любви» при влюбленности будут актуализированы значительно сильнее, чем в «обычном», "спокойном» состоянии субъекта, на что указывают изменения в его поведении и постоянство мыслей о возлюбленном, и это будет также отражаться не только при актуализации элементов этого домена, но и всех других. В методике LifeLine имеется возможность попарно актуализировать все наиболее важные события и, тем самым, иметь доступ к актуализации элементов опыта, имеющихся у субъекта. Таким образом, можно проанализировать суммарные электрические 
потенциалы мозга у влюбленных и не влюбленных в момент исследования субъектов (1), а также сравнить потенциалы мозга при актуализации самых значимых и менее значимых событий (2) и потенциалы при актуализации событий из домена «любовь" и из других доменов, предположительно не имеющих отношений к любви (3). Особенностью методики LifeLine является то, что субъекты актуализируют элементы собственного опыта, который у них разный, а не произвольного и навязанного им контента. В этом, правда, могут заключаться и трудности сопоставления, как в группах испытуемых, так и при сравнении потенциалов на разные события у разных испытуемых.

В проведенном исследовании проверялись следующие гипотезы: 1) В автобиографрическом методе «LifeLine» у влюбленных события, связанные с «объектом влюблённости», будут включены в список важных для субъекта и связаны со многими другими важными событиями. 2) Отношения между элементами опыта (событиями) у влюблённых отличны от отношений между таковыми в контрольной группе, что выражается в разной конфигурации усредненных потенциалов при актуализации событий. 3) Колебания суммарной электрической активности мозга имеют разную конфигурацию при актуализации сходных по значимости событий из домена «любовь» и других. 4) Колебания суммарной электрической активности мозга имеют разную конфигурацию при актуализации разных по значимости событий.

Методика. Первым критерием того, что испытуемый находится в состоянии влюбленности был положительный ответ на прямой вопрос «Вы влюблены?» Кроме того, всем испытуемым после исследования LifeLine (см.ниже) предлагалось пройти опросник «Шкала страстной любви» [6]. Во время работы с опросником, испытуемые оценивали степень согласия с каждым выражением, характеризующим его отношение к партнеру по шкале от 1 до 9. Общий балл представляется суммой оценок. Большее количество баллов указывает на наличие более сильной влюбленности. Все испытуемые были разделены на 5 групп в зависимости от общего балла (1- безумно влюблен; 5страстная любовь отсутствует). Работая с методикой LifeLine испытуемые фрормировали списки наиболее значимых событий их жизни (1), с указанием их дат (2) и обозначением сфрер принадлежности (3), ранжированием событий по субъективной значимости (4), а также оценивали наличие причинных и целевых связей между событиями с помощью целевого (5) и причинного (6) анализов. Таким образом, все испытуемые формировали свой список 15 таких событий, которые были индивидуальными и конфиденциальными, и могли относиться как к прошлому, так и к будущему. В результате проведения двух видов анализа были сорормированы каузоматрицы (таблица с протоколом исследования, в которой фриксируются ответы испытуемого), на основе которой строились каузограммы (графическое изображение с информацией о дате события, его 
значимости и связи событий между собой). Проводили анализ каузограммы для того, чтобы выявить, какие события являются самыми значимыми в жизни каждого участника и как они связаны с другими событиями.

Мы предположили, что поскольку значимость события является субъективной оценкой самого испытуемого, то появление навязчивых мыслей и сверхценности объекта влюбленности приведет к тому, что испытуемый будет выделять события, связанные с возлюбленным, как значимые и включать их в список событий, а сами эти события в ходе анализа будут им определены как одни из самых значимых. Во время проведения причинного и целевого анализа связи событий регистрировали суммарную электрическую активность головного мозга. Использовали электроэнцефалографр «Энцефралан-ЭЭГР19/26». Регистрация проводилась в 19 стандартных отведениях. Референтные электроды располагались на мочках правого и левого уха (объединенный ушной электрод). Сопротивление электродов не превышало 15 кОм. Полоса пропускания усилителей 0.5-70 Гц. Так же регистрировали электроокулограмму (ЭОГ) для дальнейшего исключения отрезков записи с артефактами, возникающими из-за морганий. Процедура исследования LifeLine. B начале на экране появлялись две пустые карточки, между которыми находилась точка фиксации взгляда. Далее испытуемому предъявлялась пара слов из списка, которыми испытуемый ранее обозначил события. Слова-события появлялись в карточках и располагались рядом с точкой ффиксации взгляда. События назывались одним словом, записанным малым регистром, включая в себя не более 10 букв, что позволяло минимизировать движения глаз для чтения, соответственно снижая количество артефактов в ЭЭГ, возникающих в том числе из-за саккад и морганий. Испытуемый находился на расстоянии примерно 80 см от экрана. Предварительно всем испытуемым предъявлялись придуманная упрощенная история жизни другого субъекта и, зная ее, они имели возможность потренироваться, чтобы избежать ошибки при работе, отмечая наличие или отсутствие связи между своими событиями. В первой части анализа испытуемому предлагалось сначала ответить на вопрос: “Событие, написанное слева произошло для того, чтобы достичь событие, написанное справа?», что соответствует целевому анализу по А. Кронику. Испытуемый отвечал "да» или «нет» путем нажатия на кнопки компьютерной клавиатуры, в соответствии с наличием, по его мнению, связи «цель-средство» между событиями. События предъявлялись попарно, последовательно от 1 до 15. Затем в причинном анализе вопрос изменялся на «Событие слева было потому что произошло событие справа?» В этой части события предъявлялись в обратном порядке, последовательно от 15 к 1. Способ ответа не менялся. Всего было представлено 196 пар событий. Отметки нажатий на кнопку и появления новой пары событий записывались в фрайл с данными ЭЭГ, что в последствии дало возможность 
усреднить ЭЭГ от моментов появления пары событий и моментов нажатия на кнопку после принятия решения о связи событий. В момент нажатия (ответа) в точке фиксации взгляда появлялся символ, соответствующий ответу испытуемого: + или - . Символ и предъявленная пара событий оставались на экране в течении 350 мс. После чего карточки становились пустыми, символ ответа снова менялся на точку. Экран сохранял данный вид на 350 мс. После чего в карточках появлялась названия новой пары событий, а точка в зоне фиксации взгляда не изменялась до следующего ответа испытуемого. У испытуемых не было временных ограничений для ответа.

Результаты и обсуждения результатов исследования. В исследовании приняли участие 15 испытуемых (мужчин и женщин), в возрасте от 19 до 34 лет (средний возраст составил - 23 года). Если испытуемый попадал в 1 или 2 группу по результатам опросника Шкала страстной любви (ШСЛ), а также в результате каузометрии событие, связанное с нынешней влюбленностью занимало места от 1 до 5 - испытуемый определялся в экспериментальную группу, как влюбленный. Кто попадал в группу 3 и ниже, или же значимость события, связанного с влюбленностью была ниже 5 , или событие не называлось вообще - испытуемый определялся в контрольную группу. Данные об испытуемых, и полученные результаты см. в таблице 1 .

Таблица 1.

\begin{tabular}{|l|c|c|c|c|c|c|c|} 
& $\begin{array}{c}\text { Код } \\
\text { испытуемого }\end{array}$ & $\begin{array}{c}\text { Субъективная } \\
\text { оценка }\end{array}$ & $\begin{array}{c}\text { Кол-во } \\
\text { баллов } \\
\text { ШСЛ }\end{array}$ & $\begin{array}{c}\text { Группа } \\
\text { по } \\
\text { ШСЛ }\end{array}$ & $\begin{array}{c}\text { Ранг события из } \\
\text { домена «любовь» } \\
\text { в LifeLine }\end{array}$ & Пол & Возраст \\
\hline 1 & С 0904 & Да & 84 & 3 & 15 & М & 24 \\
\hline 3 & Д1204 & Да & 100 & 2 & 1 & M & 22 \\
4 & В 1304 & Да & 103 & 2 & 7 & Ж & 19 \\
5 & Р 1504 & Нет & 59 & 4 & 10 & М & 25 \\
6 & И 1504 & Да & 112 & 1 & 0 & Ж & 19 \\
7 & П 1405 & Да & 75 & 3 & 5 & Ж & 19 \\
\hline 8 & А 1805 & Да & 111 & 1 & 1 & Ж & 22 \\
9 & Л 1905 & Да & 118 & 1 & 2,5 & Ж & 23 \\
10 & А 1905 & Да & 91 & 2 & 1 & Ж & 23 \\
11 & Л 2105 & Да & 93 & 2 & 1 & Ж & 23 \\
\hline 12 & Н 2105 & Да & 87 & 2 & 4,5 & М & 34 \\
13 & О 2405 & Да & 108 & 1 & 3 & Ж & 20 \\
14 & П 2505 & Да & 89 & 2 & 3 & Ж & 22 \\
15 & О 2605 & Да & 113 & 1 & 3 & Ж & 20 \\
\hline
\end{tabular}


Вся статистическая обработка производилась в программе SPSS Statistic 23. Ожидали, что будет выявлена значимая корреляция между шкалами «группа по ШСЛ» и «количество баллов по шкале страстной любви» с рангом в результате методики LifeLine. Провели корреляционный анализ шкал «ранг события влюбленности» и «группа по ШСЛ», а также «ранг события влюбленности» и «количество баллов по ШСЛ». Кроме того, провели корреляционный анализ субъективной оценки с рангом группы по ШСЛ и рангом события влюбленности. Была выявлена значимая корреляция между шкалами «группа по ШСЛ» и «количество баллов по ШСЛ» с рангом в результате методики LifeLine ( $R=0,665, p=0,007 ; R=-0,614, p=0,015)$. Также выявлена корреляция средней значимости между субъективной оценкой состояния и данными опроса ШСЛ $(R=0,522, p=0,46)$. Не было выявлено значимой корреляции между субъективной оценкой и рангом события влюбленности $(\mathrm{R}=-$ $0,414, p=0,125)$. Таким образом, результаты анализа данных показали, что несмотря на то, что все три вида опроса являются субъективной оценкой своей влюбленности, нет 100\% корреляции между ними. Наличие значимой корреляция между шкалами «группа по ШСЛ» и «количество баллов по ШСЛ» С рангом события в методике LifeLine позволяет использовать методику LifeLine в качестве рабочего инструмента для выявления и исследования влюбленности.

Связанные с актуализацией событий жизни потенциалы мозга. Общая конфигурация потенциалов показана на рис. 1.

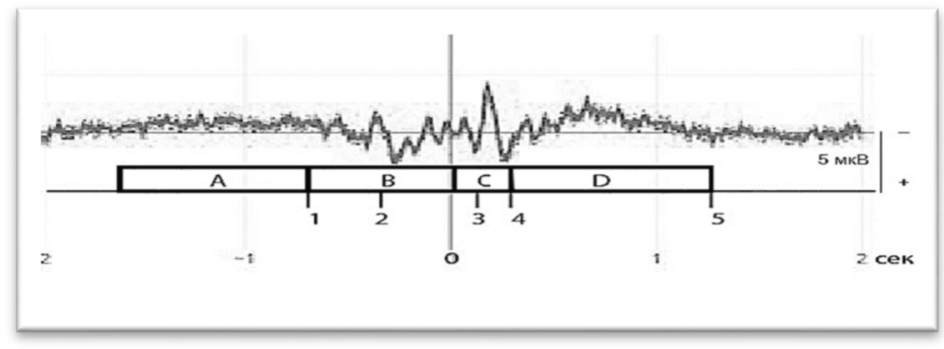

Рис. 1. Пример усредненных от появляния пар событий потенциалов мозга у одного испытуемого (С 0904) в одном из отведений ЭЭГ (Т6) (n=162 - число реализачий в усреднении)

Этапы A и D соответствуют определению наличия связи между парами разных событий, которым соответствуют медленные негативные колебания в ЭЭГ. Эти этапы заканчиваются нажатиями на кнопки клавиатуры $(1,5)$. Этап В - переход от одной пары событий к другой, и делится (2) на равные по длительности субэтапы (по 350 мсек): результаты ответа (наличие связи «+», отсутствие «-») и пустые карточки, которым соответствуют негативные и позитивные колебания ЭЭГ. Этап С- чтение названий событий $(3,4)$, 
появившихся на экране (в момент 0), которым предположительно также соответствуют негативные и позитивные колебания ЭЭГ. Следует отметить, что как в разных отведениях, так и у разных субъектов, выраженность тех или иных компонентов варьируется, вероятно, вследствие особенностей межсистемных отношений, связанных со структурой опыта индивидов.

В усредненных потенциалах мозга как от момента предъявления названий пары событий из жизни субъекта, так и от ответов на вопросы как эти события связаны, были обнаружены следующие особенности. Во-первых, выявлена разная конфигурация потенциалов в разных отведениях ЭЭГ, что может быть связано с различиями в степени представленности элементов опыта в разных областях мозга.

Во-вторых, различия конфигурации потенциалов у разных субъектов могут быть связаны с различиями в опыте, при том, что каждый из них решал одну и ту же задачу, а именно, определял наличие связи между событиями своей жизни.

При сравнении потенциалов ЭЭГ у влюбленных и невлюбленных субъектов были выявлены следующие особенности: в целом, выраженность (амплитуда) колебаний ЭЭГ у испытуемых из группы влюбленных выше, чем в контроле, то есть у субъектов в контроле более «плоская» ЭЭГ. Это, возможно, связано не только с самой структурой опыта и состоянием актуализации ее отдельных доменов (в данном случае, домена «любви»), но и более стабильной динамикой смен актов (этапов исследуемого поведения, описанного выше, см. рис. 1) у влюбленных субъектов. На данном этапе исследования провести более точный анализ данных оказалось затруднительно, в виду значительной вариабельности компонентов потенциалов ЭЭГ в разных отведениях. Вариабельность потенциалов может быть связана как с большим количеством актуализированных систем, так и с временными особенностями их актуализации. При сравнении ЭЭГ-потенциалов при установлении связей между событиями из домена «любовь», которые у влюбленных субъектов были самыми значимыми (ранг 1-5), с другими событиями, а также между другими событиями такой же значимости и «менее важными» событиями (ранг 10-15) были выявлены следующие закономерности: амплитуды колебаний на менее значимые события были больше, чем на самые значимые в отведениях Fp2 и T6. Амплитуды колебаний на самые значимые были больше, чем на такие же по значимости из домена «любовь» в отведениях Fp1, F7, F3, Fz, F8, T5, T6, 01. Обратные отношения были между амплитудами колебаний потенциалов ЭЭГ были в группе не влюбленных в данный момент, т. е., более высокие при актуализации опыта из домена «любовь». Можно было ожидать, что у испытуемых обеих групп амплитуда колебаний ЭЭГ будет большей на самые 
важные события. Однако, полученные результаты оказались иными и пока не объяснимыми.

\section{Выводы}

1. В автобиографическом методе LifeLine, события, связанные с «объектом влюблённости», оказались включены в список наиболее важных и связаны со многими другими важными событиями для субъекта. Кроме того, установлено, что события, связанные с влюбленностью, у влюбленных людей, в результате работы с методикой LifeLine являются самыми значимыми (ранг 1-5). Методика LifeLine имеет ряд преимуществ перед другими используемыми в подобных исследованиях методиках (исследуются реальные события из жизни индивида и анализируется активность мозга при актуализации этих событий).

2. У людей, находящихся в состоянии влюбленности, актуализация событий проявляется в сходной динамике потенциалов и более выраженных компонентах ЭЭГ, соответствующих установлению отношений между важными событиями их жизни, чем у не влюбленных.

3. Колебания суммарной электрической активности мозга имеют разную конфигурацию при актуализации сходных по значимости событий из домена «любовь» и других. Колебания суммарной электрической активности мозга имеют разную конфигурацию при актуализации разных по значимости событий.

4. Разнообразие событий жизни субъектов, различающихся давностью, субъективной значимостью, эмоциональной окраской, отношением к различным доменам, затрудняет интерпретацию данных ЭЭГ, полученных с использованием LifeLine, что требует модификации этого метода.

Заключение. Для исследования организации активности мозга при аддиктивных состояниях мы использовали метод автобиографического анализа LifeLine, который имеет ряд преимуществ перед опросниками, в частности, связан с актуализацией реальных событий в жизни индивида, а не с абстрактными, предложенными экспериментатором вопросами. Нами были подготовлены программы для проведения причинного и целевого анализа связей между наиболее важными событиями у влюбленных и не влюбленных в данный момент субъектов и анализа электрофизиологических данных, полученных в ходе выполнения этих видов анализа. Были выявлены некоторые особенности в организации суммарной электрической активности мозга, свойственные влюбленным, а также при сравнении самых значимых и менее значимых событий, а также событий, связанных с объектом влюбленности. Мы ожидали получить сходную конфигурацию потенциалов мозга на разные события у разных испытуемых в момент актуализации событий, а также при ответах о наличии или отсутствии связи между событиями. Однако, в разных 
отведениях у одного испытуемого, и у разных испытуемых при сравнении между собой были получены разные потенциалы, что, по-видимому, объясняется разнообразием элементов опыта (событий в памяти), различающихся давностью, субъективной значимостью, эмоциональной окраской, отношением к различным доменам, что затрудняет интерпретацию данных ЭЭГ, полученных с использованием LifeLine, что требует доработки этого метода для проведения психофизиологических исследований.

\section{Литература}

1. Головаха Е. И., Кроник А. А. Психологическое время личности. Киев, Наукова думка, 1984.

2. Егоров А.Ю. К вопросу о новых теоретических аспектах аддиктологии. Наркология и аддиктология: Сб. науч. тр. Казань, 2004, с. 80-88.

3. Короленко ц.П., Дмитриева Н.В. Психосоциальная аддиктология. Новосибирск, Изд-во «Олсиб», 2001.

4. Швырков В.Б. Введение в объективную психологию: Нейрональные основы психики. Избранные труды. - М., Изд-во «Институт психологии $\mathrm{PAH}$ », 2006.

5. Fisher H.E., Xu X., Aron A., Brown L.L. Intense, Passionate, Romantic Love: A Natural Addiction? How the Fields That Investigate Romance and Substance Abuse Can Inform Each Other, 2016.

6. Hatfield E. \& Sprecher S. Measuring passionate love in intimate relations. Journal of Adolescence, 1986, 9: pp. 383-410.

7. Zeki S., Bartels A. The neural basis of romantic love. Neuroreport, 2000, 11:3829-34.

\section{FEATURES OF THE ORGANIZATION OF BRAIN ACTIVITY IN A STATE OF LOVE}

Somik L.E. (Institute of Psychology, Russian Academy of Sciences, Moscow, Russia) Gavrilov V.V. (Institute of Psychology RAS, Moscow State University of Psychology and Education, Russia)

Falling in love is considered as a non-chemical addiction. The aim of the study was to identify the features of the organization of brain activity in a state of love. The biographical method of LifeLine [1] was chosen as the main method of detecting love. The subjects were asked to name the 15 most important events in their life, and then to analyze the connections of these events. The subjects also answered the questionnaire "Passionate love scale" [7]. A significant correlation was revealed between the questionnaire data and the data obtained in LifeLine. The results of the 
study showed that in the causogram of the subjects in love, one of the dominant events is the event associated with the beloved. The brain potentials were averaged from the moments when a pair of events appeared on the monitor screen. As a result of the EEG analysis, differences were revealed between the potentials of subjects who are in a state of love and those who are not in this state. The features of the organization of brain activity during the actualization of events from love domain and other important events from other domains were also revealed.

Keywords: falling in love, non-chemical addiction, EEG, LifeLine. 